\title{
OTONAN SEBAGAI UPAYA MEMULIAKAN MANUSIA DI BALI
}

\author{
Oleh: \\ I G A Artatik \\ Universitas Hindu Indonesia \\ Denpasar \\ ayuartatik01@gmail.com
}

\begin{abstract}
The Otonan (birthday according to Balinese calendar) ceremony once every 6 months reminds us to always appreciate and re-understand our intentions and goals again to become human beings born into this world. Being incarnated as a human being is a very important thing because only the human beings can help themselves from suffering by self-actualization and always doing good deeds to eliminate the misery of life. Related to the birth as human being, in Bhagawadgita and Sarasamuscaya, it is explained that the birth of a human being into this world is a kind of luck and glory. Because when a person is born into the world, he is given the opportunity to improve, do penance, and cleanse himself. One form of the ceremonial purification is to carry out the otonan ceremony.
\end{abstract}

Keywords: Otonan, glorifiying, Balinese people

\begin{abstract}
Abstrak
Pelaksanaan Upacara Otonan setiap 6 bulan sekali mengingatkan kita untuk selalu menghayati dan memahami kembali maksud dan tujuan kita kembali menjelma menjadi manusia lahir kedunia ini. Dengan menjelma sebagai manusia adalah suatu hal yang sangat utama karena hanya manusialah yang dapat menolong dirinya sendiri dari derita dengan jalan berbuat baik dan selalu berbuat kebajikan guna menghapuskan kesengsaraan hidup. Terkait dengan kelahiran sebagai manusia, dalam Bhagawadgita dan Sarasamuscaya dijelaskan bahwa kelahiran seorang manusia ke dunia ini adalah suatu kemujuran dan kemuliaan. Karena ketika seseorang terlahir ke dunia, dia diberi kesempatan untuk memperbaiki diri, melakukan penebusan dosa dan penyucian diri. Salah satu bentuk upacara penyucian diri adalah dengan melaksanakan upacara otonan.
\end{abstract}

Kata kunci: Otonan, Memuliakan, Manusia Bali

\section{I . PENDAHULUAN}

Dalam Kitab Suci Bhagavata Purana, Bhagavadgita serta Sarasamuscaya dijelaskan bahwa kelahiran manusia ke dunia ini adalah suatu kemujuran. Ketika seseorang lahir ke dunia, ia diberikan kesempatan untuk memeperbaiki diri, melakukan penebusan dosa dan melakukan penyucian diri. Sebab penjelmaan manusia ini adalah perwujudan karma baik dan buruk kehidupan yang terdahulu. Sedangkan di akhirat adalah tempat untuk menikmati hasil perbuatan baik dan buruk, artinya semua perbuatan baik ataupun yang buruk pahalanya akan diterima di akhirat. Setelah selesai menerima pahala itu maka akan 
kembali menjelma dengan diikuti oleh bekasbekas hasil perbuatannya.

Dengan menjelma sebagai manusia adalah suatu hal yang sangat utama karena hanya manusialah yang dapat menolong dirinya sendiri dari derita dengan jalan berbuat baik dan selalu berbuat kebajikan guna menghapuskan kesengsaraan hidup. Begitu juga dengan jalan Bhakti yakni selalu menyebutkan kebesaran Tuhan. Dan juga melakukan Tapa, Brata, Yoga dan Semadhi. Seperti yang tertuang dalam Kekawin Arjuna Wiwaha, yang bunyinya sebagai berikut "Hana mara jatma tan papiutang, tapa Brata Yoga angetul aminta wirya sukaning Widhi sahasikaia binalik aken purih ika luwih tinemunia lara, sinakitaning rajah tamah inindihaning prihati” yang artinya : "Demikian keutamaan orang yang melakukan tapa,brata dan yoga, Ia akan dapat mengentaskan derita lara. Namun sebaliknya bagi mereka yang tidak pernah melaksanakannya ia akan selalu menjumpai penderitaan".

Disamping itu juga perlu melaksanakan upacara ritual untuk penyucian diri salah satunya dengan melaksanakan upacara Otonan sebagai peringatan hari kelahirannya. Upacara Otonan ini merupakan bagian dari upacara Manusa Yadnya atau Sarira Samskara yang memiliki tujuan untuk penyucian diri lahir bhatin ( Pamarisudha Raga) dan memohon keselamatan dalam upaya peningkatan kehidupan spiritual menuju kebahagiaan baik didunia maupun di alam niskala.

Pada umumnya masyarakat Hindu di Bali rutin melaksanakan upacara otonan setiap 210 hari sekali ( 6 bulan sekali) berdasarkan perhitungan Sapta Wara, Panca Wara dan Wuku. Namun beberapa daerah di Bali upacara ini sudah ditinggalkan ketika anak - anak sudah memasuki fase remaja, utamanya pada anak perempuan. Begitu juga di daerah lainnya upacara otonan dilakukan hanya sekali saja secara besar - besaran, kemudian pada otonan berikutnya tidak dilaksanakan upacara apapun. Upacara otonan memiliki nilai - nilai yang dapat membantu manusia untuk tumbuh dan berkembang mencapai potensi terbaiknya. Maka pada kesempatan ini akan dilakukan kajian tentang upacara otonan sebagai upaya memuliakan manusia Hindu di Bali.

\section{II . PEMBAHASAN}

Upacara Otonan dan Upacara Ulang Tahun menurut Sastra Hindu pada dasarnya memiliki makna dan tujuan yang sama, yaitu untuk memperingati hari kelahiran seseorang. Namun banyak yang menambahkan makna - makna lain sehingga perayaan ulang tahun berkembang menjadi banyak versi. Di era globalisasi ini momen ulang tahun dirayakan dengan sangat meriah dan tidak pernah terlepas dari Kue Ulang Tahun, kado dan acara tiup lilin. Berkenaan dengan acara tiup lilin pada perayaan ulang tahun, ada pandangan yang berbeda menurut Kitab suci Manawa Dharmasastra. Dalam Kitab ini ditegaskan bahwa "Seseorang tidak boleh meniup api karena api adalah Agni sebagai penghantar setiap Yadnya yang dilakukan seseorang. Seseorang yang meniup api akan berkurang kecerdasannya" Bagi umat Hindu yang menyakini Weda seharusnya menyalakan api pada hari Ulang Tahunnya bukan meniupnya, karena lilin atau api mengandung kekuatan atau cahaya yang terang. Seperti yang tertuang dalam Rigveda Samhita, "Tamaso ma jyotir gamaya, Semoga kami pergi dari kegelapan menuju cahaya yang terang. Artinya menyalakan lilin atau api berarti memohon kepada Tuhan agar diberikan cahaya pengetahuan tentang keinsyafan diri. Terkait dengan kelahiran sebagai manusia, dalam Bhagawadgita dan Sarasamuscaya dijelaskan bahwa kelahiran seorang manusia ke dunia ini adalah suatu kemujuran dan kemuliaan. Karena ketika seseorang terlahir ke dunia, dia diberi kesempatan untuk memperbaiki diri, melakukan penebusan dosa dan penyucian diri.

Salah satu bentuk upacara penyucian diri adalah dengan melaksanakan upacara otonan. Upacara otonan adalah salah satu bentuk upacara yang tergolong dalam upacara Manusa Yadnya. Berbeda dengan hari ulang tahun yang dilaksanakan setiap setahun sekali, upacara otonan dilaksanakan setiap 210 hari atau 6 bulan sekali. Otonan adalah salah satu bentuk upacara untuk membersihkan si anak dari segala mala yang dibawa dari sejak ada dalam rahim ibu yang dipengaruhi oleh Sang Catur Sanak. Tjok Rai Sudharta ( 2013; 36 ) dalam buku Manusia Hindu dari Kandungan sanpai Perkawinan, menjelaskan bahwa tahapan tahapan kehidupan manusia Hindu dari masa 
prenatal sampai satu weton, adalah sebagai berikut, " pada waktu baru lahir bersama si anak keempat saudaranya ( Catur Sanak) itu bernama Bhuta Nyom, Bhuta Rah, Bhuta Ari - Ari dan Bhuta Tabunan, dan setelah dibuatkan upacara namanya akan diganti menjadi: Angga Pati, Raja Pati, Banaspati, Banaspati Raja “.

Dalam menghadapi kehidupan sehari - hari umat manusia selalu dihadapkan pada prilaku yang bersifat baik dan yang bersifat buruk. Dalam hal ini tentu saja pikiran menjadi ladasan utama manusia untuk berbuat maupun berkata baik dan buruk, berdasarkan hal tersebut manusia perlu melaksanakan yadnya, yaitu salah satunya dengan melaksanakan upacara manusa yadnya. Manusa yadnya adalah pemeliharaan, pendidikan serta penyucian secara spiritual terhadap orang sejak terwujudnya jasmani dalam kandunga sampai akhir hidupnya. Penyucian merupakan factor utama dalam upacara otonan.

Pelaksanaan upacara otonan atau sering juga disebut Pawetonan tentu saja dilengkapi dengan sarana banten otonan seperti banten Pras sebagai symbol permohonan kehadapan Sang Hyang Widhi dalam wujudnya sebagai Tri Murti guna menyucikan Tri Guna ( sifat Sattwam, Rajah,Tamah), banten Pengambean yang dilengkapi dengan Tulung sebagai symbol permohonan ketegaran dan keteguhan untuk menghadapi tantangan hidup kedepan serta mendapatkan dan memberikan pertolongan dalam hidupnya, Dapetan sebagai symbol harapan agar selalu diberikan kesejahtraan dan kebahagiaan, panjang umur dan sehat walafiat, Sesayut sebagai symbol permohonan kerahayuan dalam menjalini kehidupan di dunia ini, Penyeneng sebagai symbol kehidupan yang panjang ( panjang umur), yang dilengkapi dengan benang Tetebus sebagai symbol sebagai penebusan segala apa yang perlu ditebus, dan jenis banten lainnya. Banten Otonan ini merupakan permohonan yang ditujukan kepada Sang HyangDumadi, Bhatara Hyang Guru serta Ida Sang Hyang Widhi Wasa atau manifestasinya yang memberkahi dan melindungi selama hidup di dunia ini dan bertujuan untuk keselamatan dan diberikan umur panjang ( dirgayusa).

Menurut tradisi masyarakat Hindu di Bali, dalam mengantarkan doa-doa Otonan mempergunakan doa dalam bentuk See (doa dalam bahasa Bali). Dimana doa ( See) yang diucapkan oleh penganteb upacara otonan memberikan pengaruh psikologi terhadap orang yang melaksanakan otonan, karena saat nganteb (mesee) sekaligus dilakukan pemberian symbol-simbol sebagai telah menerima anugrah dari kekuatan doa tersebut. Seperti contoh, saat melingkarkan benang tetebus dipergelangan tangan orang yang meoton, dengan see " Ne cening megelang benang, apang meuwat kawat me balung besi " yang artinya Ini kamu memakai gelang benang, supaya berotot kawat dan berbalung besi). Begitu juga saat natab banten Sesayut, didahului dengan memegang dan memutar dulang Sesayut searah jarum jam ( Purwa daksina ) dengan See sebagai berikut " $N e$ cening ngilehan sampan, ngilehan perahu, batu mekocok, tungked bungbungan, teked dipesisi napetang perahu bencah, mangde ada anak nulungi" yang artinya ; Ini kamu memutar sampan, memutar perahu, batu mekocok, tongkat bungbung, sampai dipantai menemui kapal terdampar agar ada orang yang menolong. Alangkah luhurnya makna doa yang diucapkan dalam pelaksanaan otonan bagi masyarakat Hindu di Bali yang dikemas dengan berbagai symbol yang dapat dimaknai secara fisik maupun psikologis, dengan harapkan agar anak - anak yang menjadi tumpuan harapan keluarga mendapatkan kekuatan dan kemudahan dalam mengarungi kehidupan.

Pelaksanaan upacara otonan kalau dipandang dari filsafat agama tentang penentuan waktu enam bulan Bali, memiliki tujuan antara lain, dilihat dari angka 210 hari merupakan angka samkhya, kalau dijumlahkan akan menjadi angka tiga. Angka tiga ini merupakan simbul bahwa mulai aktifnya Tri Pramana : sabda, bayu, dan idep. Sedangkan kalau dilihat dari angka enam yang mengandung makna sebagai symbol Sadripu. Dengan adanya sifat - sifat sadripu yang dibawa dari lahir, maka perlu diadakan pelaksanaan upacara otonan dengan tujuan menjadikan manusia yang memiliki prilaku yang baik, beretika dan berbudi pekerti yang luhur sesuai dengan ajaran agama Hindu.

Dari uraian ini, dapat diambil hikmahnya bahwa menjadi manusia sangat utama dan mulia, maka sangat perlu menjalankan swadarmanya sebagai manusia termasuk melaksanakan upacara otonan setiap enam bulan sekali sesuai hari kelahirannya. Namun di era globalisasi sekarang ini akibat kemajuan 
tehnologi dan keterbatasan waktu dan pengetahuan umat tentang upakara, maka pelaksanaan upacara otonan telah mengalami pergeseran bahkan banyak mengabaikan upacara otonan sebagai peringatan hari kelahirannya. Kenyataannya sekarang banyak umat Hindu yang dengan berbagai alasan, masih tetap melaksanakan otonan walaupun dengan pelaksanaan yang sangat sederhanan dan juga lebih senang mengadakan peringatan Hari Ulang Tahun (ULTAH) dengan lebih meriah. Padahal perayaan Ulang Tahun yang dirayakan dengan pesta pora, potong kue dan tiup lilin bukan merupakan tradisi Hindu di Bali karena tidak mengandung unsur penyucian diri serta tidak menggunakan upakara bebantenan yang diiringi dengan doa dan mantra. Upakara bebantenan mengandung kekuatan magis, dimana kekuatan magis yang dimaksud adalah sebagai penetralisir sifat - sifat manusia yang asubha karma dikendalikan kearah subha karma.

\section{III . PENUTUP}

Menurut tradisi masyarakat Hindu di Bali, Otonan adalah peringatan hari kelahiran bagi umat Hindu yang datang dan diperingati setiap 210 hari ( 6 bulan ) sekali berdasarkan perhitungan Sapta Wara, Panca wara dan Wuku. Otonan merupakan peringatan hari yang khusus atau special karena setiap orang mempunyai hari kelahiran yang berbeda antara satu dengan yang lainnya. Dalam tradisi masyarakat Hindu di Bali merayakan Hari Ulang Tahun bukanlah merupakan suatu hal yang wajib untuk dilakukan, akan tetapi berbeda halnya dengan Otonan. Karena saat otonan kita memanjatkan puji syukur kehadapan Sang Hyang Widhi diberikan kesempatan menjelma kembali menjadi manusia, serta mohon keselamatan dan kesejahtraan dalam menempuh kehidupan dengan menggunakan sarana Banten atau Upakara yang penuh dengan makna dan simbul - simbul suci.

Pelaksanaan Upacara Otonan setiap 6 bulan sekali mengingatkan kita untuk selalu menghayati dan memahami kembali maksud dan tujuan kita kembali menjelma menjadi manusia lahir kedunia ini. Adapun tujuan dari pentingnya kita melaksanakan Upacara Otonan adalah sebagai berikut :

- Secara Spiritual adalah bertujuan untuk membersihkan dan penyucian diri dengan sarana bebantenan.

- Secara Lahiriah adalah bertujuan menyegarkan ingatan setiap manusia agar selalu merenungkan kembali kesempatannya menjelma menjadi manusia yang merupakan mahluk Ciptaan Tuhan yang paling sempurna yang memiliki Tri Pramana. 


\section{DAFTAR PUSTAKA}

Aldin,Alfatri,2007, Spiritualitas dan Realitas Kebudayaan Kontemporer, Yogyakarta \& Bandung. Jalasutra.

Connolly,Peter. 2009, Aneka Pendekatan Penelitian Agama, Yogyakarta; LKis

Geriya, I Wayan, 2008, Transformasi Kebudayaan Bali Memasuki Abad XXI, Surabaya:Paramita.

Kajeng, I Nyoman dkk. 2009, Sarasamuscaya, Surabaya; Paramita

Mas Putra, I Gusti Agung, 2002, Upakara Yadnya, Jakarta; Proyek Peningkatan Sarana / Prasarana Kehidupan Beragama Tersebar di Sembilan(9) Kabupaten Kota

Maswinara, I Wayan,2004, Rg Veda Samhita Mandala IV,V,VI,VII, Surabaya;Paramita

Pitana, I Gde,1994, Dinamika Masyarakat dan Kebudayaan Bali, Denpasar; BP

Pudja,G.MA,SH, dan Tjok Rai Sudartha, 1981, Manawadharmasastra, Weda Smerti yang Dikodifikasikan Kedalam Hukum Hindu, Jakarta; Departemen Agama Dir.Jendral Bimas Hindu dan Budha

Surayin, Ida Ayu Putu, 2002. Manusa Yadnya ( Seri II Upakara Yadnya), Surabaya. Paramita Sri Srimad A C, 2010, Bhagawad Gita ( Menurut aslinya), Jakarta; Hanuman Sakti

Sudarsana, Ida Bagus Putu, 2009, Himpunan Tetandingan Upakara Yadnya, Denpasar, Anom

Sudhartha, Tjok Rai,2013, Manusia Hindu dari Kandungan Sampai Perkawinan, Denpasar; Pustaka Bali Post

Triguna, Ida Bagus Gde Yudha, 1997, Materi Pokok Sosiologi Hindu, Jakarta; Derektorat Jendral Masyarakat Hindu Budha

Wiana, I Ketut, 2009, Suksmaning Banten, Jakarta; Pustaka Manik Geni

Widana, I Gusti Ketut, 2015, Banten Siap Saji Konsumerisme Di Panggung Ritual, Denpasar. Bali Post 